\title{
EXECUTIVO E LEGISLATIVO NO BRASIL PÓS-CONSTITUINTE
}

\author{
Filomeno Moraes \\ Professor de Mestrado em Direito Constitucional da Universidade de Fortaleza e de Mestrado em Politicas Públicas \\ e Sociedade da Universidade Estadual do Ceará
}

Resumo: O artigo descreve o estatuto dos poderes Executivo e Legislativo na Constituição do Brasil de 1988
e, considerando o processo político no País, analisa a dinâmica dos dois poderes.
Palavras-chave: separação de poderes; Executivo-Legislativo; democracia.

O presidencialismo, o princípio da proporcionalidade e a Federação são instituições típicas da vida politica brasileira contemporânea. Ademais, são traços constitutivos do ideário e da prática democrática saudável pelo mundo afora;

no Brasil e no resto do mundo, são igualmente passiveis

de aperfeiçoamento; de permanente aperfeiçoamento.

Olavo Brasil de Lima Jr.

$\mathrm{O}$ presente trabalho trata da separação de poderes na dinâmica política brasileira, sob a Constituição Federal de 1988. Atendo-se fundamentalmente à configuração do Executivo e do Legislativo e ao processo político que se desenrola no País, estrutura-se através dos seguintes itens: separação de poderes - princípio constitucional e práxis política; presidencialismo ou parlamentarismo?; o presidencialismo e o conflito Executivo versus Legislativo; presidencialismo de coalizão; processo decisório e relações Executivo x Legislativo; medidas provisórias e Poderes Executivo e Legislativo; considerações finais.

\section{SEPARAÇÃO DE PODERES: PRINCÍPIO CONSTITUCIONAL E PRÁXIS POLÍTICA}

O reafirmar da separação de poderes como princípio estruturante da ordem político-constitucional brasileira inau- gurada em 1988 coroa uma tradição de quase dois séculos com a separação de poderes do Estado como princípio constitucional. Acrescente-se, porém, que no último processo constituinte atribuiu-se ao princípio a condição de "cláusula pétrea", isto é, não passível de ser abolido através de emenda à Constituição, como forma de configurar seu caráter de imprescindibilidade para a efetivação do Estado Democrático de Direito (Moraes Filho, 2000).

De fato, desde a Constituição de 1824, que normatizou a separação de poderes sob a influência da teoria de Constant (1989), adotando um modelo quatripartido - Poderes Moderador, Legislativo (respectivamente Real e Representativo, na terminologia de Constant), Executivo e Judiciário -, o princípio da separação de poderes tem sido uma das pilastras do Constitucionalismo nacional. Mas se as Constituições brasileiras, inclusive as de 1967 e 1969 (para não lembrar a Carta de 1937) entronizaram o princípio, rendendo assim, no geral, seu tributo ao sistematizador da lei mais abrangente do poder - quem o detém tende a dele abusar (Montesquieu, 1979) -, a desordem constitucional pós-64 o desfigurou, proclamando-o muito mais como uma espécie de homenagem do vício à virtude do que como pedra angular do edifício constitucional, tal a concentração de poderes armazenados no Executivo e o amesquinhamento do Legislativo e do Judiciário.

Assim, a reafirmação do princípio da separação de poderes pela Constituição de 1988 possui também o sentido 
de operação restauradora, para afastar a desfiguração levada a efeito pelo processo autoritário mais recente. Cumpre lembrar, porém, que a idéia de que nem a constituição nem a lei são capazes de, por si sós, modificar a natureza das coisas ou das instituições não é incompatível com a filosofia subjacente ao Do Espirito das Leis. O mesmo já havia sido intuído pelo teórico pioneiro do Estado moderno, quando, n'O Príncipe, observou que “(...) há tamanha distinção entre como se vive e como se deveria viver, que aquele que trocar o que se faz por aquilo que se deveria fazer aprende antes sua ruína do que sua preservação" (Maquiavel, 1996:73).

Por conseguinte, a compreensão do princípio da separação de poderes não pode limitar-se à sua configuração normativo-constitucional, fazendo-se necessária a integração dessa configuração com o processo político efetivo.

\section{PRESIDENCIALISMO OU PARLAMENTARISMO?}

O conflito entre o Executivo e o Legislativo tem sido historicamente crítico para a estabilidade democrática no Brasil, constituindo traço do processo político em boa medida considerado tanto pelos que preferem o presidencialismo quanto pelos que são favoráveis ao parlamentarismo.

Didaticamente, pode-se dizer que, a rigor, duas características se destacam nos sistemas presidencialistas: o presidente reclama total legitimidade democrática; o presidente é eleito para um período de tempo, que, sob circunstâncias normais, não pode ser modificado, encurtado ou (em virtude de dispositivos constitucionais vigentes nos países que proíbem a reeleição) prolongado. Por sua vez, pode-se afirmar que, no parlamentarismo, o governo deriva sua autoridade da confiança do Parlamento, seja das maiorias parlamentares seja da tolerância parlamentar em relação aos governos minoritários. A diferença básica em relação ao presidencialismo dá-se pelo fato de que, no último sistema, o povo elege de modo direto e por período determinado o chefe do Executivo, a quem são outorgados, pela Constituição, poderes para decidir a composição do ministério e para exercer o controle da administração. O Chefe do Executivo é o chefe simbólico do Estado; dentro do período para que foi eleito, só pode ser afastado pelo remédio excepcionalíssimo do impeachment.

A consciência da problemática do sistema de governo tem dirigido o esforço para a busca de alternativas para esse traço do dilema institucional. Assim, setores das elites políticas pretendem, com a adoção do parlamentarismo, di- minuir os riscos da ingovernabilidade e da instabilidade institucional. Na sua avaliação, o parlamentarismo faria definhar os elementos de ineficiência e incerteza do sistema político, extirpando características imperiais vislumbradas no presidencialismo.

No debate, tanto durante o Congresso Constituinte (1987-1988), quanto durante a campanha que antecedeu o plebiscito, previsto no Ato das Disposições Constitucionais Transitórias, realizado em 21 de abril de 1993, vislumbrou-se, em linhas gerais, a seguinte taxinomia dos parlamentaristas brasileiros: os parlamentaristas puros preferiam um sistema no qual o Chefe de Estado fosse eleito indiretamente, talvez segundo o modelo da Alemanha Ocidental; os parlamentaristas mitigados aceitavam a figura de um ministro-coordenador ou um gabinete com forte influência presidencial (o modelo finlandês), mas não um primeiro-ministro que dependesse verdadeiramente da confiança parlamentar; finalmente, havia os adeptos do parlamentarismo dual, a saber, aqueles que aceitavam um sistema semelhante ao francês, contanto que o mecanismo de escolha do primeiro-ministro e sua atuação fossem mais claramente parlamentaristas do que o previsto na Constituição da França (Lamounier, 1991; Moraes Filho, 1993).

É razoável afirmar que no Brasil, de modo geral, acentuou-se a tendência à aceitação do modelo de influência predominantemente francesa, ou seja, um sistema de governo intermediário entre o presidencialismo e o parlamentarismo, o qual tem recebido uma série de denominações: sistema semipresidencialista, sistema semiparlamentarista, sistema de Executivo bipolar ou de Executivo dividido, república presidencialista-parlamentarista, república quase-presidencialista ou república quase-parlamentarista. Variações de um sistema que tem funcionado de maneiras diversas, se caracterizam fundamentalmente por ter um presidente, indireta ou diretamente eleito, e também um primeiro-ministro, que depende da confiança do Parlamento. Nele o presidente tem, potencial ou realmente, poder para interferir nas políticas públicas e no processo decisório.

Por oportuno, em relação ao "modelo francês", lembremos a condenação radical proferida por Bonavides (1992) e a advertência de Linz (1991-1995), a saber: "O sistema de Executivo bipolar pode funcionar realmente bem, e já o fez (ainda como diz Suleiman, com consideráveis tensões e disfunções), quando a maioria eleitoral que apóia o presidente também elege a maioria para o Parlamento, e quando o presidente tem uma considerável autoridade dentro do seu partido e este partido é forte no legislativo", mas "a incom- 
patibilidade entre um presidente com poderes consideráveis e a maioria parlamentar pode levar a um sério impasse, gerando uma crise no sistema político".

\section{O PRESIDENCIALISMO E O CONFLITO EXECUTIVO VERSUS LEGISLATIVO}

No presidencialismo, dois procedimentos distintos respondem pela composição do Executivo e do Legislativo. Enquanto o Executivo é constituído, pela própria natureza das coisas, com base no voto de toda a nação, o Legislativo é formado por representantes de parcialidades. Na literatura brasileira, há inclusive uma interpretação prestigiosa que vislumbrou, como causa do conflito político que levou a República Populista à crise, a origem distinta das bases de legitimidade do Poder Executivo e do Poder Legislativo, a saber: o voto urbano e o voto de características predominantemente rurais (Furtado, 1967).

A rigor, nos Estados contemporâneos, e essa não é característica isolada do Brasil, pode-se dizer que o Executivo conseguiu mais representatividade do que o Legislativo. Aqui mais ainda, por conta do presidencialismo, pois, quando é o eleitorado que escolhe diretamente o governante, neste fundem-se as expectativas e as esperanças populares, num grau que jamais a eleição de um deputado poderá igualar (Ferreira Filho, 1995).

Mas, conforme diagnosticam Lamounier e Nohlen (1993:50-51), à hipertrofia do Executivo corresponde, em contrapartida, uma fragilidade. Veja-se: “(...) chegamos, nesse período de sessenta anos, desde a Revolução de 1930, ao que chamaria de equilibrio de duas fragilidades. De um lado, o Poder Executivo, cujo titular sofre erosão vertiginosa em seu capital político e freqüentemente não dispõe de meios legítimos para refazê-lo, uma vez erodida a base eleitoral originária; do outro lado, o Congresso, cuja composição reflete o alto grau de fragmentação e o caráter consociativo do sistema político na sua vertente eleitoral, partidária e federativa. Ou seja, um sistema político que tenderá, com altíssima probabilidade, a produzir governos, em acentuada minoria, contrapontos a essa fragmentação do Poder Legislativo".

As duas fragilidades seriam agravadas em decorrência da seguinte situação: em primeiro lugar, porque os formuladores de políticas do Executivo - portadores do viés tecnocrático - não conhecem, normalmente, as instituições e os processos que caracterizam a política; em segundo, porque os membros do Legislativo não se sentem responsáveis pela formulação da política nacional e dedicam-se pri- mordialmente à representação de interesses regionais, corporativos ou clientelísticos.

Embora parte da literatura mais recente argumente na direção contrária (v.g., Abrucio, 1998) ao que foi acentuado por Lamounier e Nohlen, para alguns, no Brasil de hoje, o fantasma do presidencialismo imperial está cada vez mais presente. Uma observadora da cena política nacional aduz: "Nunca vi na história brasileira, em períodos que não são considerados ditaduras, uma tal concentração de poderes. O presidente concentra poderes do Legislativo, do Executivo e do Judiciário. Quando pressiona o Judiciário, quando impede ações diretas de inconstitucionalidade. Ele exercita o poder por meio de milhares de medidas provisórias. Isso caracteriza o presidencialismo imperial. (...)" (Benevides, 1998:12).

Evidentemente, mesmo que se torne relativa a tese do presidencialismo imperial, não se pode deixar de observar os reforços que a introdução do mecanismo da reeleição ocasiona no que concerne às características do presidencialismo brasileiro. Não se pode desprezar que a reeleição, com os incentivos que acarreta para a personalização do poder, pode tornar mais problemática a consolidação da democracia política no País, sobretudo por conta dos mecanismos de enfraquecimento partidário que acarreta (Mainwaring, 1995; Moraes Filho, 1998 e 1999).

Ora, se o Legislativo tem poderes para vetar medidas propostas pelo Executivo, e o Executivo nada pode contra o Legislativo, tende-se a desenhar situação geradora de confrontos, com probabilidades de impasses e, por conseqüência, ingovernabilidade. A crise da República Populista, com o desenlace manu militari em 1964, foi em boa medida uma crise de paralisia decisória (Santos, 1982), oriunda da incapacidade do Executivo - frente a um Legislativo hostil - de tomar decisões políticas adequadas em relação à crescente crise do Estado. No momento, todavia, como se discutirá a seguir, o processo político nacional não toma a direção da paralisação decisória nem da ingovernabilidade.

\section{PRESIDENCIALISMO DE COALIZÃO}

O Congresso Constituinte rejeitou o parlamentarismo, mantendo a tradição republicana presidencialista, interrompida apenas no período 1961-1963. Por sua vez, o plebiscito, que trouxe ao debate público brasileiro um extenso e variado leque de temas político-institucionais (Sadek, 1995), também resultou na manutenção do presidencialismo, reforçado, através da Emenda Constitucional no 16 , de 
1997, com a inserção no sistema político da possibilidade de reeleição do presidente da República.

Na verdade, sob a nova ordem constitucional, desenvolveu-se um padrão de governança que a literatura denomina "presidencialismo de coalizão" (Abranches, 1988 e 2001; Figueiredo e Limongi, 1999; Santos, 2001), cujo principal eixo de impacto está na relação entre os Poderes Executivo e Legislativo. E, como afirma Abranches (2001): "Por ser presidencialismo, esse regime de governança reserva à presidência um papel crítico e central, no equilíbrio, gestão e estabilização da coalizão. O presidente precisa cultivar o apoio popular - o que requer a eficácia de suas políticas, sobretudo as econômicas - para usar a popularidade como pressão sobre sua coalizão; ter uma agenda permanentemente cheia, para mobilizar atenção da maioria parlamentar e evitar sua dispersão; ter uma atitude proativa na coordenação política dessa maioria, para dar-lhe direção e comando".

A Constituição Federal dotou o Presidente da República de possibilidades muito grandes de influência na legislação, de muitos mecanismos de intervenção no processo legislativo. Na verdade, os poderes de agenda do Presidente da República vão desde a capacidade para editar medidas provisórias com força de lei, o que permite ao presidente implementar sua agenda, sobretudo de natureza econômica e administrativa, superando possíveis obstáculos congressuais. Por outro lado, a constante utilização das medidas e a necessidade de reeditá-las periodicamente para manter sua continuidade normativa acabam por congestionar a pauta dos trabalhos legislativos, contraindo o tempo destinado ao exame de outras matérias, possivelmente de origem no próprio Legislativo (Santos, 2000).

Ademais, o presidente da República tem a seu dispor ampla iniciativa das leis complementares e ordinárias. E possui a iniciativa privativa da legislação, entre outras matérias, sobre o plano plurianual, as diretrizes orçamentárias e os orçamentos anuais, além da iniciativa das leis que fixem ou modifiquem os efetivos das Forças Armadas, disponham sobre a criação de cargos, funções ou empregos ou aumento de sua remuneração, dos servidores públicos da União, criação, estruturação e atribuições dos Ministérios e órgãos da administração pública. Também não se admite aos parlamentares o aumento de despesas nos projetos de iniciação exclusiva do Presidente da República.

Esse amplo monopólio permite ao agente que inicia manipular estrategicamente a distribuição de preferências do agente que aprecia, pois, se o agenda setter conhece as preferências do Legislativo, simbolizado pela figura do le- gislador mediano, é possível àquele calibrar o envio da proposta de forma a maximizar a própria utilidade, bastando para isso que o projeto se encontre no interior da curva de preferência da maioria congressual (Santos, 1997).

Por sua vez, o Presidente da República tem a prerrogativa de solicitar urgência nos projetos de lei de sua iniciativa, o que permite abreviar os prazos de tramitação de sua agenda e retira dos órgãos diretivos e comissões legislativas a possibilidade de engavetamento de proposições que contrariem os interesses do primeiro.

Em que pesem essas prerrogativas do Poder Executivo, é evidente que, em contrapartida, mesmo executivos dotados de fortes poderes legislativos não podem governar contra a vontade da maioria parlamentar, pois proposições legislativas só são aprovadas se obtiverem apoio das maiorias.

\section{PROCESSO DECISÓRIO E RELAÇÕES EXECUTIVO X LEGISLATIVO}

A análise sistemática da dinâmica institucional brasileira, sob a Constituição de 1988 , e tendo por foco o processo decisório no Congresso Nacional, encontrou na formulação das políticas públicas fonte alternativa de explicação a respeito da interação Executivo-Legislativo. E, contra as manifestações resenhadas anteriormente, em relação à hipertrofia cum fragilidade do presidencialismo brasileiro, encontram-se evidências teóricas, empíricas e analíticas que, detalhando a operação dos mecanismos institucionais, denotam razoável grau de apoio obtido pelo Presidente da República, sob a ordem constitucional inaugurada em 1988, de modo a afastar o fantasma da paralisia decisória e da ingovernabilidade.

$\mathrm{Na}$ verdade, o estado da arte da Ciência Política brasileira permite hoje maior conhecimento do sistema político. Antes, a ausência de pesquisas sistemáticas, mormente sobre os Poderes Executivo e Legislativo, e o seu relacionamento, ocasionou a proliferação de juízos negativos e predições catastróficas sobre o comportamento parlamentar e partidário e o papel do Congresso no sistema decisório nacional, juízos e predições diretamente deduzidos da normatividade referente ao sistema de governo, eleitoral e partidário vigente (Figueiredo e Limongi, 1999).

Mas as novas pesquisas - principalmente as que, retirando do sistema de governo e da legislação eleitoral e partidária o foco de análise sobre as relações ExecutivoLegislativo, o redirecionam para a estrutura do próprio processo decisório e do seu impacto no comportamento 
parlamentar e no desempenho governamental - chegam a resultados que questionam muito do que se afirma sobre o sistema político nacional. Sobretudo põem por terra juízos que, sem a devida base empírica, orientam parte das elites políticas a sustentar um conjunto de propostas de reforma institucional capaz de promover verdadeira subversão pelo alto (Santos, 1994; Tavares, 1998).

A observação das regras de organização interna do Congresso Nacional e a extensão dos poderes legislativos do Presidente da República permitem, por conseguinte, que se tirem conclusões mais pertinentes sobre o funcionamento do sistema político brasileiro e que se dê uma explicação abrangente para o sucesso do Executivo na aprovação de sua agenda legislativa, o comportamento disciplinado dos parlamentares e o apoio partidário obtido pelos diferentes governos brasileiros sob a vigência da Constituição de 1988.

A análise da recente experiência presidencialista no Brasil revela que o Congresso não é uma instância de veto à agenda do Executivo. Aliás, conforme já chamaram a atenção Shugart e Carey (1992), não é verdade que, sob presidencialismos (considere-se a relevância das variações institucionais do sistema presidencial de governo) todo e qualquer parlamentar utiliza apenas a estratégia de agir irresponsavelmente e não cooperar com o Executivo. Este - dependendo do arranjo político-constitucional - pode dispor de recursos que induzam os parlamentares a cooperar com o governo e a sustentá-lo. O controle exercido pelo Executivo sobre a iniciativa legislativa cria incentivos para que os parlamentares se juntem ao governo apoiando sua agenda.

No Brasil pós-88, observa-se que a disciplina partidária germina no seio do próprio Congresso. Mesmo admitindo que a legislação eleitoral leve os parlamentares a cultivar uma atitude individualista, deve-se ressaltar que as políticas de cunho distributivista garantidoras desse tipo de conexão eleitoral dependem do acesso à arena decisória. Assim, o controle centralizado sobre a agenda legislativa impede que as estratégias do "voto pessoal" sejam dominantes. O controle da agenda exercido pelos líderes partidários e pelo Executivo reduz a chance de sucesso das iniciativas individuais dos deputados, dado que os líderes são capazes de reduzir suas oportunidades.

Decerto, as normas que regulam a distribuição dos recursos parlamentares dão origem a um padrão altamente centralizado de organização do Congresso, que se harmoniza com o papel preponderante do Executivo, tendo os partidos políticos a estruturar esse padrão centralizado, por força regimental. E esse estado de coisas acarreta problemas que a ordem democrática tem de superar.

Há, todavia, elementos empíricos suficientes para negar o diagnóstico, dominante na literatura, segundo o qual o Brasil atravessa, ou vive na iminência de atravessar, uma crise de governabilidade decorrente do conflito entre um Executivo institucionalmente frágil e um Legislativo fortalecido pela Constituição de 1988, mas incapaz de agir em virtude da ausência da necessária estrutura partidária. O estudo sistemático do comportamento dos partidos políticos no Congresso robustece o argumento de que os mesmos desempenham importante papel no Legislativo.

A disciplina partidária verificada nas votações nominais (Figueiredo e Limongi, 1999) do Congresso Nacional refuta a tese segundo a qual a forma de governo e as leis eleitorais e partidárias são os únicos determinantes do comportamento parlamentar. Observe-se que o Executivo - de onde se origina a maioria das leis promulgadas no País - raramente tem suas proposições legislativas rejeitadas pelo Congresso, evidenciando que não existem dificuldades nem restrições intransponíveis à capacidade do Executivo para ter suas proposições transformadas em lei.

$\mathrm{O}$ Executivo brasileiro organiza o apoio à sua agenda legislativa em bases partidárias, em moldes muito similares àqueles encontrados em regimes parlamentaristas. $\mathrm{O}$ Presidente da República distribui as pastas ministeriais com o objetivo de obter o apoio da maioria dos legisladores; partidos que recebem pastas são membros do governo e devem comportar-se como tal no Congresso, votando a favor das iniciativas patrocinadas pelo Executivo.

A literatura tende a descartar a possibilidade de que coalizões partidárias em apoio ao Executivo se formem e funcionem a contento sob o presidencialismo. No Brasil pós-Constituinte, os presidentes organizam ministérios em bases partidárias, e as coalizões assim construídas tendem a funcionar no Congresso (Meneguello, 1998; Figueiredo e Limongi, 1999).

\section{MEDIDAS PROVISÓRIAS E PODERES EXECUTIVO E LEGISLATIVO}

Certamente, o mais poderoso instrumento de que dispõe o Poder Executivo para afirmar sua agenda política está estabelecido pelo art. 62 da Constituição Federal de 1988, que lhe garante a faculdade de editar, em casos de relevância e urgência, medidas provisórias com força de lei, por trinta dias, a partir do ato de sua edição. Os constituintes de 87/88 puseram à disposição do Presidente da República 
um mecanismo que lhe assegura poderes muito alentados e, até hoje, senadores e deputados federais não propiciaram a regulamentação necessária para evitar o abuso na sua utilização, nem o Supremo Tribunal Federal balizou o uso do mecanismo.

Na verdade, lembre-se de que só no governo Sarney, através de medidas provisórias, todas posteriormente admitidas e transformadas em lei pelo Congresso Nacional, o presidente da República determinou condições de registro provisório para estrangeiro no país, estabeleceu o efetivo da polícia no Estado de Roraima, estipulou regras para a loteria federal, inscreveu os nomes Tiradentes e Deodoro da Fonseca no Livro dos Heróis da Pátria (Arantes, 1997). A observação das medidas provisórias editadas aponta que o instrumento tem sido utilizado também em incursões desestabilizadoras da garantia constitucional do devido processo legal, com as modificações abruptas da legislação processual civil.

Extrapolando os requisitos constitucionais da "urgência" e da "relevância", o uso indiscriminado do recurso às medidas provisórias constitui, de fato, delegação indiscriminada de competências, a desatar a dissolução da ordenação democrática das funções constitucionalmente estabelecida em 1988. E pode, se não controlado institucionalmente, acarretar a ruptura do núcleo essencial dos limites de competência constitucionalmente fixado, para pedir de empréstimo a expressão de Canotilho (1992).

A visão dominante sobre os efeitos da utilização das medidas provisórias tende a pressupor que a separação de poderes no sistema presidencialista implica a existência de interesses divergentes no Executivo e no Legislativo. Por essa razão, essas medidas são geralmente vistas como instrumentos eficazes com que o Executivo conta para superar resistências e impor sua vontade ao Congresso. Assim, governos minoritários recorreriam mais freqüentemente à edição de medidas provisórias. Mas, como ressaltam Figueiredo e Limongi (1999:14), “as medidas provisórias podem ser instrumentos ainda mais poderosos nas mãos de um Executivo que conte com maioria no Congresso, especialmente em governos de coalizão. Nesses casos, podem funcionar como um eficaz mecanismo de preservação de acordos e de proteção da coalizão governamental nas decisões contra medidas impopulares”.

\section{CONSIDERAÇÕES FINAIS}

Considerado apenas o processo político brasileiro mais recente, é notório que se tem vivido um longuíssimo pro- cesso de transição, o qual tem os seus primórdios por volta de 1974, quando o autoritarismo burocrático - inaugurado dez anos antes - começava a sua inflexão. Aquilo que tem sido denominado a primeira transição, ou seja, o lapso entre as primeiras medidas liberalizantes e a passagem de governos autoritários para governos democratizantes, no Brasil obedeceu a um calendário extremamente lento e gradual, findando-se somente em 1985, com a vitória de Tancredo Neves no Colégio Eleitoral.

A segunda transição, aquela que assiste à consecução de um regime democrático, tem sido, por seu turno, problemática, a ponto de ser crucial a interrogação sobre o grau de consolidação da democracia política entre nós. Importantes analistas denominam a situação político-institucional brasileira como "democracia vazia", "democracia pobre" ou "democracia delegativa", para expressar a fragilidade da mesma, sobretudo sua incapacidade para lidar com a crise econômica e com a crise social.

A análise política sistemática também tem destacado que, nas democracias novas, como a brasileira, estão presentes, combinados, pelo menos dois componentes perversos, a saber: uma grande distância entre as normas formais e o funcionamento da maioria das instituições políticas; o particularismo como uma instituição política dominante. O segundo componente - o particularismo - refere-se aos vários tipos de relações não universalistas, desde as relações particularistas hierárquicas, como a patronagem e o nepotismo, os favores e jeitinhos, até as ações que, do ponto de vista das normas jurídicas vigentes, seriam consideradas corruptas. O particularismo é antagônico a um dos principais aspectos do complexo institucional de qualquer democracia política mais enraizada, qual seja a distinção comportamental e legal entre a esfera pública e a esfera privada (O’Donnell, 1996).

Por isso, sem desprezar o patente progresso relativo à convivência democrática no Brasil nos anos recentes, é inquestionável o caráter atrofiado, truncado, de muitas das instituições políticas. Por conta disso, em grande medida, a organização política brasileira tem problemas no que diz respeito ao processamento da diversidade do País e à expressão da pluralidade de interesses e valores socialmente subjacentes. Esse caráter delegativo (e pouco representativo, por conseqüência) tem raízes mais antigas, oriundas de uma formação histórica de forte ênfase no Poder Executivo, da vocação eminentemente anti-representativa enquistada na cultura política brasileira e da recorrência ao autoritarismo, o qual, desgraçadamente, tem imprimido 
no desenvolvimento político nacional uma lógica de ciclos de contração e ciclos de abertura política.

Temeu-se que, na Nova República, a instabilidade das coalizões governamentais pudesse atingir diretamente a Presidência da República e que, no Congresso, a polarização tendesse a transformar coalizões secundárias e facções partidárias em coalizões de veto, elevando perigosamente a probabilidade de paralisia decisória e a conseqüente ruptura da ordem política. Antecipou-se, no limite, um cenário possível em que o presidente se tornasse cativo da vontade do seu partido, delegando a própria autoridade - situação de equilíbrio precaríssimo e de alto risco para a própria estabilidade da ordem democrática, ou cenário alternativo em que o presidente resolvesse enfrentar o partido, confrontar o Parlamento e afirmar a sua autoridade numa atitude bonapartista ou cesariana altamente prejudicial à normalidade democrática (Abranches, 1988).

Isso, todavia, não aconteceu. Pelo contrário, observa-se que os riscos de crises institucionais cíclicas diminuem, e as praxes políticas parecem estar dando soluções sem necessidade de maiores inovações formais. Sobretudo, e esta é a maior conclusão que se tira deste estudo, o processo político brasileiro, embora enfrente problemas e dilemas, tem caminhado para evitar o conflito disruptivo entre o Executivo e o Legislativo, que foi um dos traços marcantes e perversos de sua evolução político-constitucional anterior a 1988 .

\section{NOTAS}

E-mail do autor: filomeno@secrel.com.br

Uma primeira versão deste artigo foi apresentada no XXIV Symposium on Portuguese Traditions, promovido pela Universidade da Califórnia, Los Angeles - UCLA nos dias 21 e 22/04/2001.

\section{REFERÊNCIAS BIBLIOGRÁFICAS}

ABRANCHES, S.H. "Presidencialismo de Coalizão: O Dilema Institucional Brasileiro". Dados. Rio de Janeiro, Iuperj, v.31, n.1, 1988, p.5-34.

"Presidencialismo de Coalizão e Crise de Governança". Conjuntura Política. Belo Horizonte, Associação Brasileira de Ciência Política - ABCP; Departamento de Ciência Política UFMG (www.cevep.ufmg.br/bacp), n.26, jun. 2001.

ABRUCIO, F.L. Os barões da Federação: Os governadores e a redemocratização brasileira. São Paulo, Editora Hucitec/Departamento de Ciência Política - USP, 1998.

ARANTES, R.B. Judiciário e Política no Brasil. São Paulo, Idesp/ Ed. Sumaré/Fapesp/Educ, 1997.

BENEVIDES, M.V. "Cidadão comum está abandonado" (entrevista). Jornal do Brasil, Rio de Janeiro, 05/07/1998, p.12.
BONAVIDES, P. "Considerações sobre o Parlamentarismo". O Povo. Fortaleza, 18/10/1992, p.25A.

BRASIL. Constituição Federal. 5a ed. São Paulo, Ed. RT, 2000.

CANOTILHO, J.J.G. Direito Constitucional. $2^{\text {a }}$ ed. Coimbra, Ed. Almedina, 1992.

CONSTANT, B. Princípios políticos constitucionais: princípios políticos aplicáveis a todos os governos representativos e particularmente à Constituição atual da França (1814). Rio de Janeiro, Liber Juris, 1989.

FERREIRA FILHO, M.G. Do processo legislativo. $3^{\mathrm{a}}$ ed. São Paulo, Ed. Saraiva, 1995.

FIGUEIREDO, A. e LIMONGI, F. Executivo e Legislativo na Nova Ordem Constitucional. Rio de Janeiro, Ed. FGV, 1999.

FURTADO, C. "O Brasil ou os entraves ao desenvolvimento". Paz e Terra. Rio de Janeiro, n.4, 1967, p.165-81.

LAMOUNIER, B. (org.). A opção parlamentarista. São Paulo, Idesp/ Ed. Sumaré, 1991.

LAMOUNIER, B. e NOHLEN, D. (orgs.). Presidencialismo ou Parlamentarismo - Perspectivas sobre a reorganização institucional brasileira. São Paulo, Idesp/Ed. Loyola, 1993.

LIMA Jr., O.B. de. Instituições políticas democráticas: o segredo da legitimidade.

LIMONGI, F. et alii. Forma de governo, leis eleitorais e poder agenda. Caxambu-MG, paper apresentado no XXIII Encontro Anual da Anpocs, mimeo, 1999.

LINZ, J. "Presidencialismo ou parlamentarismo: faz alguma diferença?". In: LAMOUNIER, B. (org.). A opção parlamentarista. São Paulo, Idesp/Ed. Sumaré, 1991, p.61-120.

MAINWARING, S. "Brazil: Weak Parties, Feckless Democracy". In: MAINWARING, S. e SCULLY, T.R. (eds.). Building Democratic Institutions: Party Systems in Latin America. Stanford - CA, Stanford University Press, 1995, p.354-98.

MAQUiAVEL, N. O Príncipe. $2^{\text {a }}$ ed. São Paulo, Martins Fontes, 1996.

MENEGUELlo, R. Partidos e governos do Brasil contemporâneo (1985-1997). São Paulo, Paz e Terra, 1998.

MONTESQUIEU, C.L. de S. Do espirito das leis. $2^{\text {a }}$ ed. São Paulo, Abril Cultural, 1979.

MORAES FILHO, J.F. de. "A discussão sobre o parlamentarismo e seus parâmetros". Nomos. Fortaleza, Mestrado em Direito - UFC, v.11/12, n.1/2, 1993, p.195-204.

. A construção democrática. Fortaleza, UFC/Casa José de Alencar, 1998.

. "Cinzas da reeleição”. O Povo. Fortaleza, 21/09/1999, p.7A.

A separação de poderes no Brasil: teoria, princípio constitucional e práxis política. Tese de Livre-Docência. Fortaleza, Universidade Estadual do Ceará - UECE, mimeo, 2000.

O’DONNELL, G. "Otra Institucionalización". La Política - Revista de Estudios sobre el Estado y la Sociedad. Buenos Aires, n.2, 1996, p.5-27.

SADEK, M.T. "Opciones institucionales y consolidación democrática: un análisis del plebiscito de 1993 en Brasil”. In: PERELLI, C.; PICADO, S. e ZOVATTO, D. (compiladores). Partidos y clase politica en América Latina en los 90. San José-Costa Rica, IIDHCapel, 1995, p.365-85.

SANTOS, F. "Patronagem e poder de agenda na política brasileira". Dados. Rio de Janeiro, Iuperj, v.40, n.3, 1997, p.465-92.

. "A dinâmica legislativa do Rio de Janeiro: análise de uma legislatura”. II Encontro da Associação Brasileira de Ciência Política. São Paulo, mimeo, 2000. 
"O nome do jogo II". Conjuntura política. Belo Horizonte, Associação Brasileira de Ciência Política; Departamento de Ciência Política - UFMG, n.26, jun. 2001 (www.cevep.ufmg.br/ bacp).

SANTOS, W.G. dos. Sessenta e quatro: anatomia da crise. São Paulo, Vértice/Ed. RT, 1982.
Regresso: máscaras institucionais do liberalismo oligárquico. Rio de Janeiro, Opera Nostra, 1994.

SHUGART, M.S. e CAREY, J. Presidents and Assemblies. Constitutional Design and Electoral Dynamics. Cambridge, Cambridge University Press, 1992.

TAVARES, J.A.G. Reforma politica e retrocesso democrático. Porto Alegre, Mercado Aberto, 1998. 